IOSR Journal of Engineering

e-ISSN: 2250-3021, p-ISSN: 2278-8719,

Vol. 2, Issue 12 (Dec. 2012), ||V3|| PP 34-40

\title{
Non destructive approach to crocodile eggs harvesting
}

\author{
Elisha. Mabunda ${ }^{1}$ and Lovemore Kagande ${ }^{2}$ \\ ${ }^{1}$ Department of Electrical Engineering; University of Zimbabwe, P. O. Box MP 167, Mt Pleasant, Harare, \\ ${ }^{2}$ Department of Mechanical Engineering, University of Zimbabwe, P.O. Box MP167, Mt Pleasant, Harare
}

\begin{abstract}
The characteristic behavior of crocodile breeding farmers in Zimbabwe and the North of Africa was studied during the period 2010 to 2011 . In particular the study was concerned with the behavior of young crocodiles just before they hatch. This was done to answer the question of how to prevent the destruction of crocodile eggs during harvest time by farmers. The result of this study lead to the production of an electronic circuit that detects the presence of crocodile eggs without breaking them; thereby reducing the number of eggs destroyed every egg harvest time. Following the study of how young crocodiles behave just before they hatch, electronic sound detectors were used to listen to the activities of the young crocodiles before hatching. The result of this finding was used to construct an electronic circuit that can be used to locate the eggs in their natural habitat and avoid destroying them.
\end{abstract}

Keywords: crocodile egg harvesting, Sound transducer, chip, filter, Integrated circuit (IC)

\section{INTRODUCTION}

Crocodile farming has become a lucrative business venture in Zimbabwe, with lots of financial incentives to both the farmer and the nation. Unfortunately many farmers in Zimbabwe currently use very oldfashioned, destructive methods to harvest the crocodile eggs from their natural habitat. The loss can greatly be reduced by employing modern technologies that avoid unnecessary breaking of eggs during the harvesting process.

Farmers in Zimbabwe locate the crocodile nests that are normally buried in the sand along river bands by a crude destructive method. Farmers use a metal spike that they drive into the sand on the suspected places. When the end of this spike comes out with traces of known constituents of crocodile eggs, they then conclude that the sport has a crocodile nest. They then carefully dig it out to collect the eggs for hatching at secure homes. This approach is very destructive and results in a number (three or more eggs per trial) of eggs being inadvertently destroyed. The product described here under, if adopted by farmers will minimize, if not eliminate the wanton destruction of crocodile eggs during harvesting.

\section{MATERIALS AND METHODS}

Crocodiles lay between 30 and 100 eggs at any given time. Eggs are found in the sand buried for safety during incubation. The nest is located 5 meters to 12 meters from the edge of the ${ }^{`}$ 1river or lake. Hatching takes $1 \frac{1}{2}$ to 3 months. It is during this period that egg detection is crucial. Young crocodiles start making chirping sounds or "umph! umph! umph!" sounds which are perfectly audible to humans and such sounds alert the others in the nest of the onslaught of the hatching process, according to the report in the June 23rd issue of Current Biology. Those cries also sound an alarm for the mother croc to start digging up the nest.

The frequency range for these sounds is approximately $300 \mathrm{~Hz}$ to $3000 \mathrm{~Hz}$.

To design this crocodile egg detector, the following procedure was adopted:

- Compute the centre frequency from the geometric mean value, using the following formula for the geometric mean:

Centre Frequency $f c$ squared is equal to Upper Frequency $f_{H}$ multiplied by Lower Frequency $f_{L}$, such that $f c^{2}=\mathrm{f}_{\mathrm{H}} \times \mathbf{f}_{L}$

- Use a sound transducer (in this case, a microphone) to detect the sound from the sand.

- A band pass filter is used to cut off unwanted frequencies that are outside the required frequency band.

- An audio amplifier is used to drive heard phones or earphones.

The device detects the presence of the crocodile eggs by detecting the chirping sounds produced by the young crocodiles during hatching. This is achieved by the sound transducer picking up the sound signals and subsequently converting them to electrical signals. The band pass filter passes only the desired frequency range. Only the frequencies close to the centre frequency are allowed to pass. The filter circuit is connected to an 
audio amplifier to raise the level of the sound signal to a level high enough to drive either a loudspeaker or headphones. The speaker converts electrical signals back to sound waves within the audio frequency range (ie the range that can be detected by a human ear).

Figure 1 is a block diagram that describes the process that takes place during crocodile egg detection.

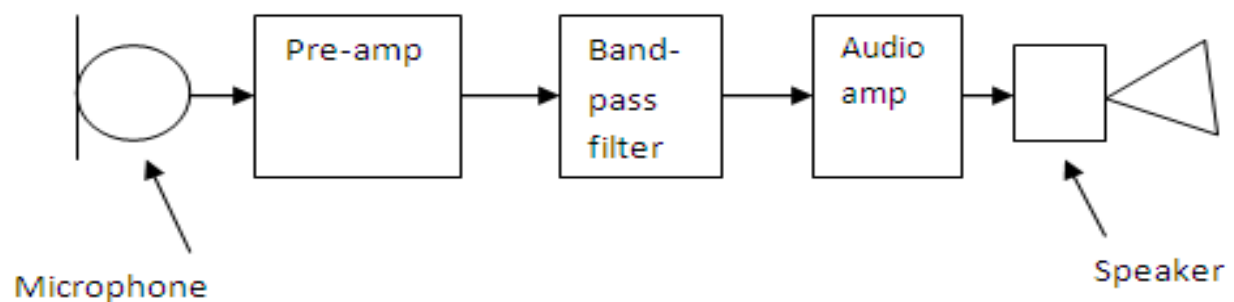

Fig. 1 System block diagram

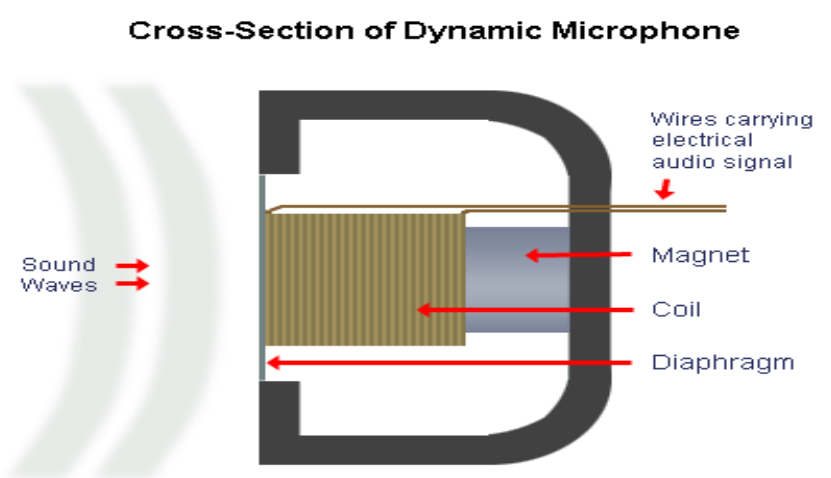

Fig 2 inside the microphone

Any microphone can be used but for this product a dynamic microphone is chosen, asit is readily available. The microphone produces an electrical signal from the movement of the diaphragm as a result of air pressure due to sound waves as shown in fig. 2 above. This electrical signal is very weak, typically in the order of milli-volts, which is the reason why the microphone is connected after the pre-amplifier in order to boost the signal to a level of approximately 1 volt before it is applied to the microphone. In this circuit the microphone pre-amplifier signal is applied to a combination of buffer and filters, with the buffer serving the purpose of isolating the two sections of the filter.

Due to the buffer amplifier the filter output produces a signal voltage that is capable of driving an audio amplifier connected before the speaker or headphones, as shown in fig 3 below.

C1 Buffer-amp

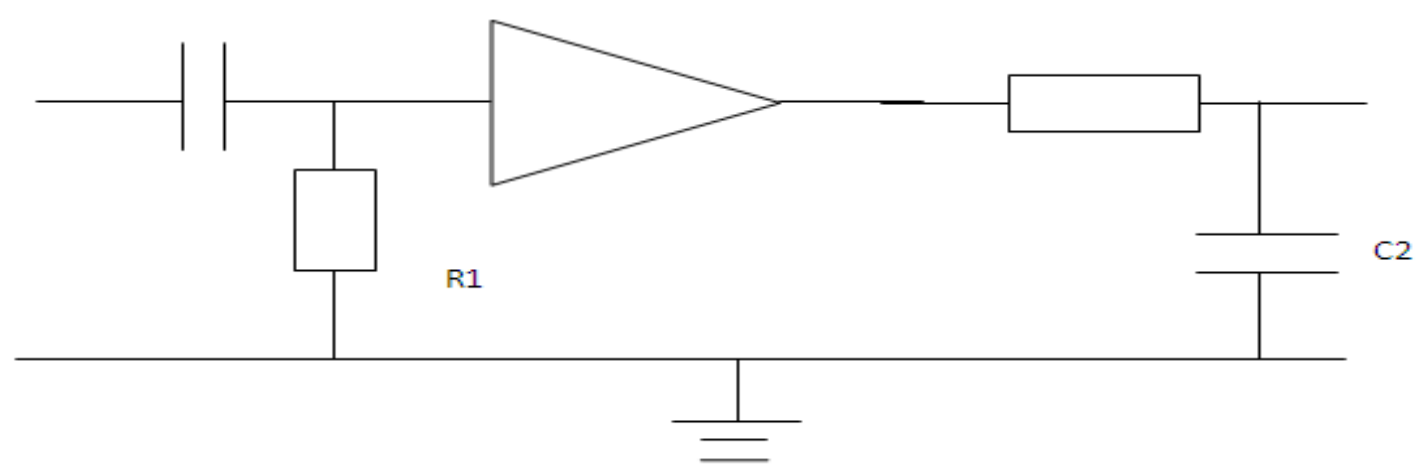

Fig 3. Filter circuit with a buffer

\section{The design objectives can be summarized as follows:}

- $\quad$ To produce a device that will detect the presence of crocodile eggs without destroying any of them.

- To produce a sensitive pickup transducer, 
- $\quad$ To produce a filter that will discriminate frequencies outside the required range of $300 \mathrm{~Hz}$ to $3000 \mathrm{~Hz}$.

- To raise the signal to a level sufficient to successfully drive a speaker or a pair of headphones.

\section{MICROPHONE PRE-AMPLIFIER DESIGN} as LM 358

The microphone pre-amplifier is based on the amplifier chip that has a very low supply current known

\section{LM358 technical specifications}

The LM358 integrated circuit (IC) consists of high gain internal frequency-compensated operational amplifier. It operates from a single power supply over a wide range of voltages. Operation from a split power supply is also possible. The low power supply current drain is independent of the magnitude of the power supply voltage.

In the linear mode the input common-mode voltage range includes ground and the output voltage can also swing to ground even though operated from only a single power supply voltage. The unity gain cross frequency is temperature-compensated. The input bias current is also temperature-compensated. The IC has very low supply current draintypically $500 \mu \mathrm{A}$ ) essentially independent of supply voltage.

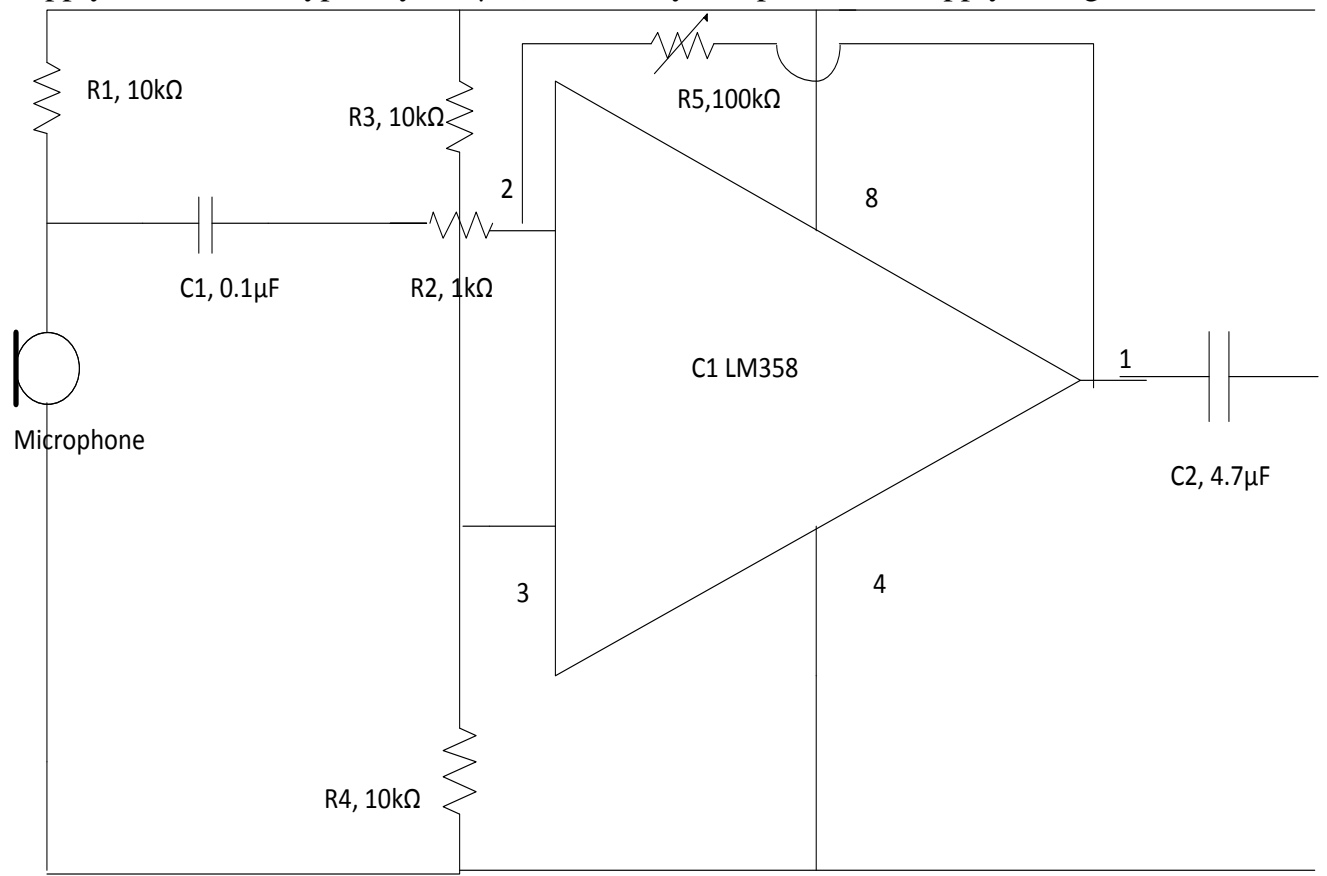

Sound transducer pre-amplifier

Fig. 4 Microphone pre-amplifier

The microphone amplifier is designed around the LM 358 IC. The gain of the amplifier is adjusted by a variable resistor R5, to give any desired output that can derive the audio amplifier.

\section{List of components for the microphone amplifier:}

IC1 LM 358 integrated circuit

$\mathrm{R} 1, \mathrm{R} 3$, and $\mathrm{R} 4=10 \mathrm{k}$ ohms resistors

$\mathrm{R} 2=1 \mathrm{k}$ ohm resistor

R5 $\quad=100 \mathrm{k}$ ohm to $1 \mathrm{M}$ ohm variable resistor (potentiometer)

C1 $\quad=0.1 \mu \mathrm{F} / 16 \mathrm{~V}$ capacitor

$\mathrm{C} 2 \quad=4.7 \mu \mathrm{F} / 16 \mathrm{~V}$ capacitor.

Function(s) of each of the components are as detailed below:

C1 couples the weak signal picked by the sound transducer, while $\mathrm{C} 2$ couples the output of the preamplifier to the input of the band pass filter. This arrangement ensures that the signal is not unduly attenuated by passive components that make the band pass filter.

The choice of $\mathrm{C} 1$ and $\mathrm{C} 2$ is such that the frequency range of interest is passed without any attenuation. 
$\mathrm{R} 1$ provides the dc bias to the microphone while R3 and R4 provide bias to the non- inverting input of the operational amplifier pin 3. Pin 2 provides the means of interfacing the microphone signal to the pre-amplifier. Pins 4 and 8 of the operational amplifier supply the IC with DC electrical power. Pin 1 is the output going into the band pass filter.

\section{The band -pass Filter}

The filter design approach is that of passive RC components, to realize a band pass filter. This is achieved by implementing two filters, i.e. the Low pass filter and the High pass filter. To improve on the sensitivity of the filter the two sections are separated by a buffer amplifier that isolates and eliminates the losses introduced by the passive elements.

To produce a Band Pass filter we combined the High pass filter with the low pass filter, as shown in fig 4. below

R1

C1

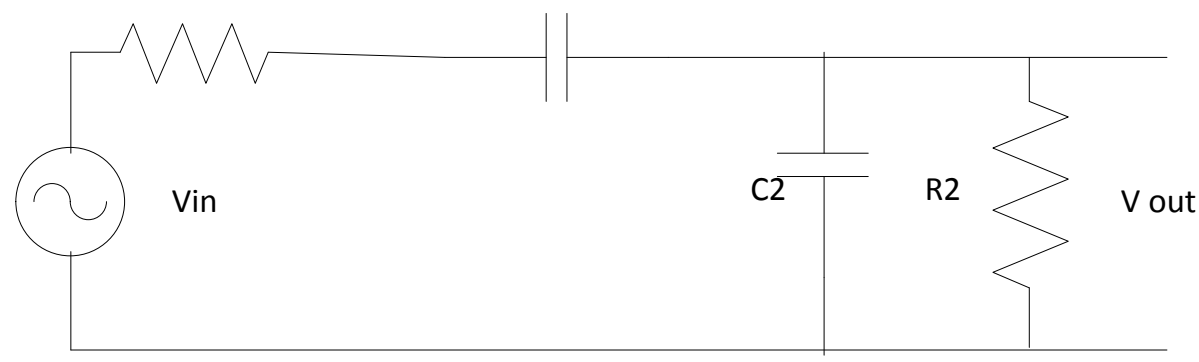

Fig.5. Band Pass filters without a buffer.

$\mathrm{R} 1=\mathrm{R} 2=\mathrm{R}$ are set to $10 \mathrm{k}$ ohms we then calculate the values of $\mathrm{C}_{1}$ and $\mathrm{C}_{2}$ as follows:

$$
\begin{array}{ll}
\mathbf{C}_{\mathbf{1}} & =\frac{1}{2 \pi f c R}=\frac{1}{2 \pi \times 300 \times 10000}=53.1 \mathbf{n F} \\
\mathbf{C}_{2} & =\frac{1}{2 \pi f c R}=\frac{1}{2 \pi \times 3000 \times 10000}=5.3 \mathbf{n F}
\end{array}
$$

To compute the Centre frequency we use the Geometric Mean.

Centre Frequency $=f_{\mathrm{C}}=\sqrt{f L * f H}=\sqrt{300 * 3000}$

Where $F_{\mathrm{c}}$ is the centre frequency, $f_{\mathrm{L}}$ is the lower frequency and $f_{\mathrm{H}}$ is the higher frequency, whereupon $f_{C}=$

\subsection{Hz}

The output of the filter is fed into the audio amplifier that raises the signal to the required level for the speaker. The implementation of this amplifier is realized by use of an Integrated Circuit (IC). This has the advantage of power saving and compactness of the final product.

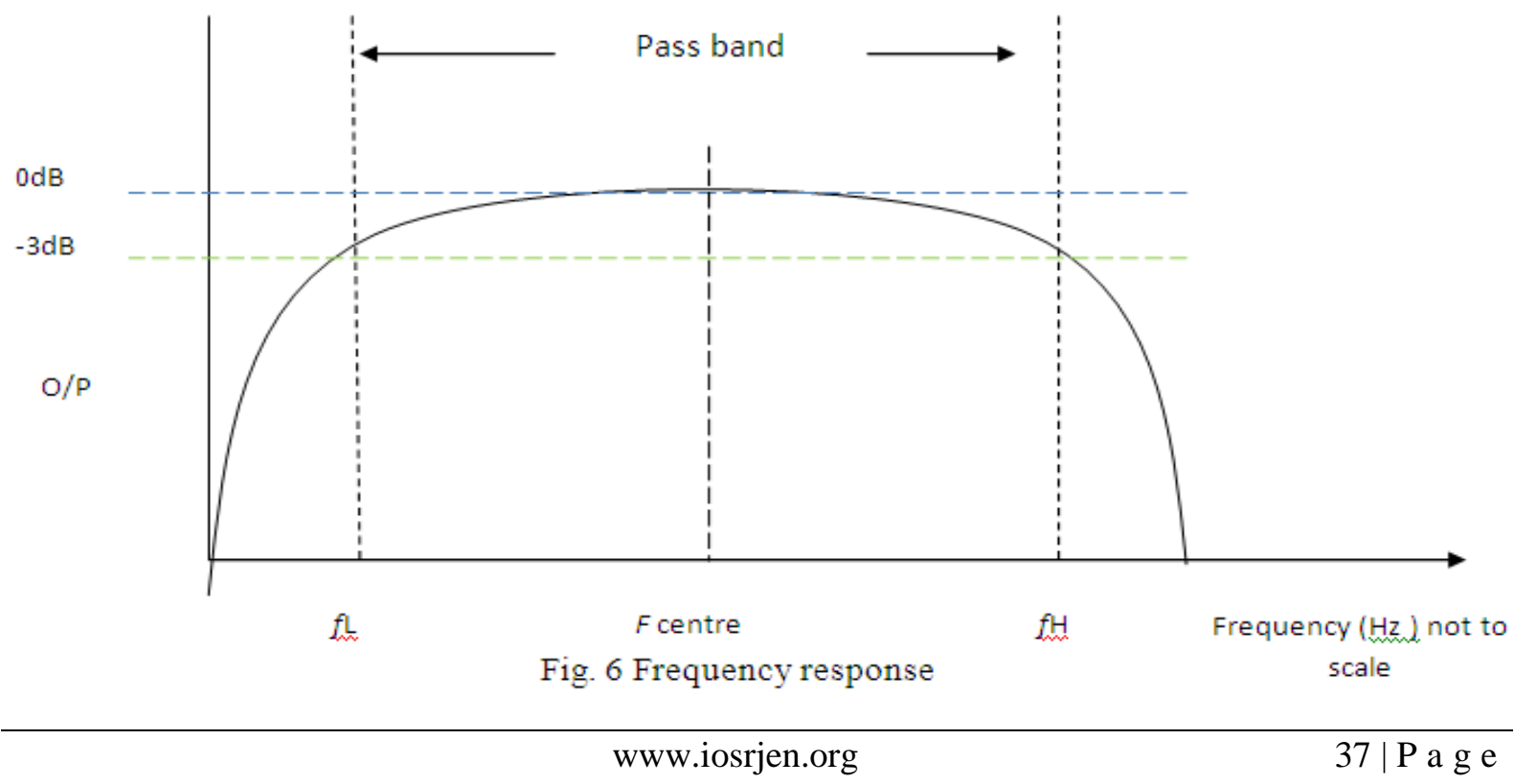




\section{Audio amplifier design}

The last section of the crocodile egg detector before the electrical transducer is the audio amplifier. The amplifier is made from IC LM386. The LM386 is a power amplifier designed for use in low voltage consumer applications. The gain is internally set to 20 to keep external part count low, but the addition of an external resistor and capacitor between pins 1 and 8 will increase the gain to any value from 20 to 200, depending on the values chosen.

The inputs are ground referenced while the output automatically biases to one-half the supply voltage. The quiescent power drain is only 24 mill watts when operating from a 6 volt supply, making the LM386 ideal for battery operation.

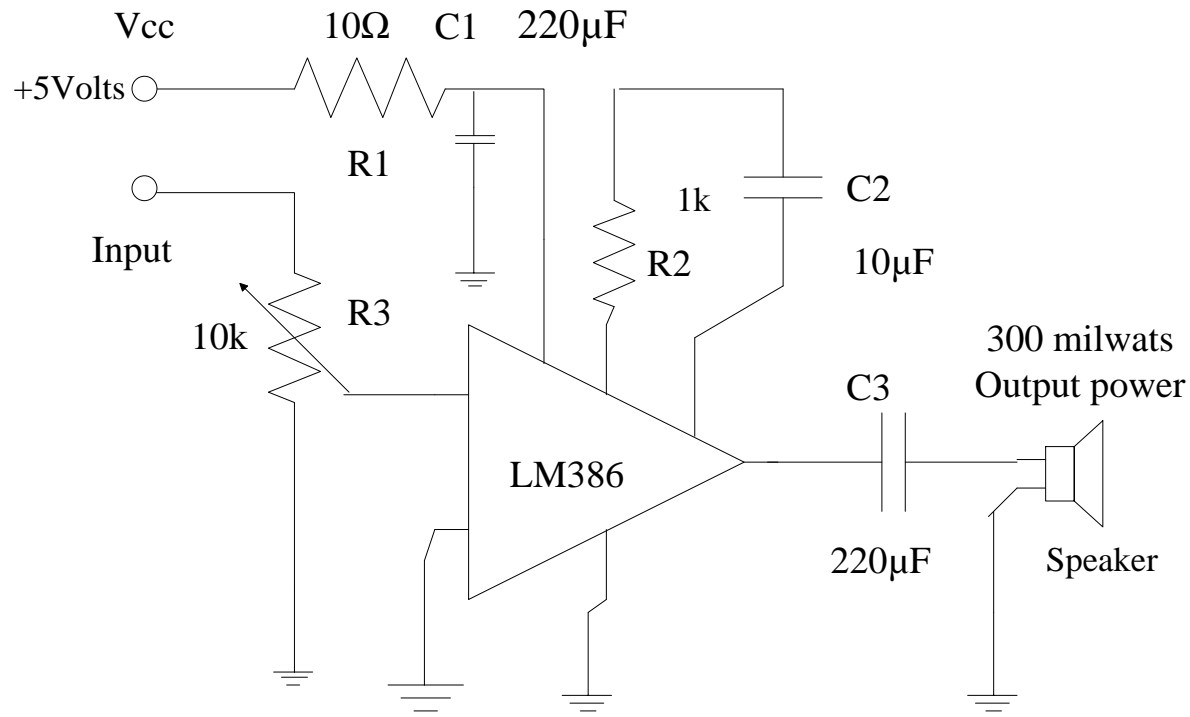

Fig. 8. Audio amplifier based on LM386 IC

Due to the use of this type of the IC the following is achieved:

Battery operation supply voltage range: $4 \mathrm{~V}-12 \mathrm{~V}$

Minimum external parts

Low quiescent current drain: $4 \mathrm{~mA}$

Voltage gains from 20 to 200

Ground referenced input

Self-centering output quiescent voltage

Low distortion: $0.2 \%\left(\mathrm{~A}_{\mathrm{V}}=20, \mathrm{~V}_{\mathrm{S}}=6 \mathrm{~V}, \mathrm{R}_{\mathrm{L}}=80 \mathrm{Ohm}, \mathrm{P}_{\mathrm{O}}=125 \mathrm{~mW}\right.$, at a frequency of $1 \mathrm{kHz}$

where $\mathrm{A}_{\mathrm{V}}=$ gain and $\mathrm{V}_{\mathrm{S}}=$ supply voltage $\mathrm{R}_{\mathrm{L}}=$ effective load and $\mathrm{P}_{\mathrm{O}}$ output power

\section{SYSTEM TESTING}

The tests for the system were based on the lab equipment available. This included the signal generator, regulated power supply, the oscilloscope and the audio speaker. The major component that decides the success of this project is the Band Pass filter. The test on the filter showed that the same does pass the required bandwidth of $911.5 \mathrm{~Hz}$ to $986.3 \mathrm{~Hz}$ centered on the $948.7 \mathrm{~Hz}$.

The complete system was tested using a signal generator as the main source of sound, at a frequency range of $300 \mathrm{HZ}$ to $3000 \mathrm{~Hz}$. To simulate the crocodile eggs buried under the sand a voltage of $100 \mathrm{mV}$ was used instead of the $300 \mathrm{mV}$ that could be detected from the eggs when on the surface. The sound level produced measured to 0.5 Watts with both presets adjusted to center position. This level is adequate to drive headphones or a small loud speaker. 


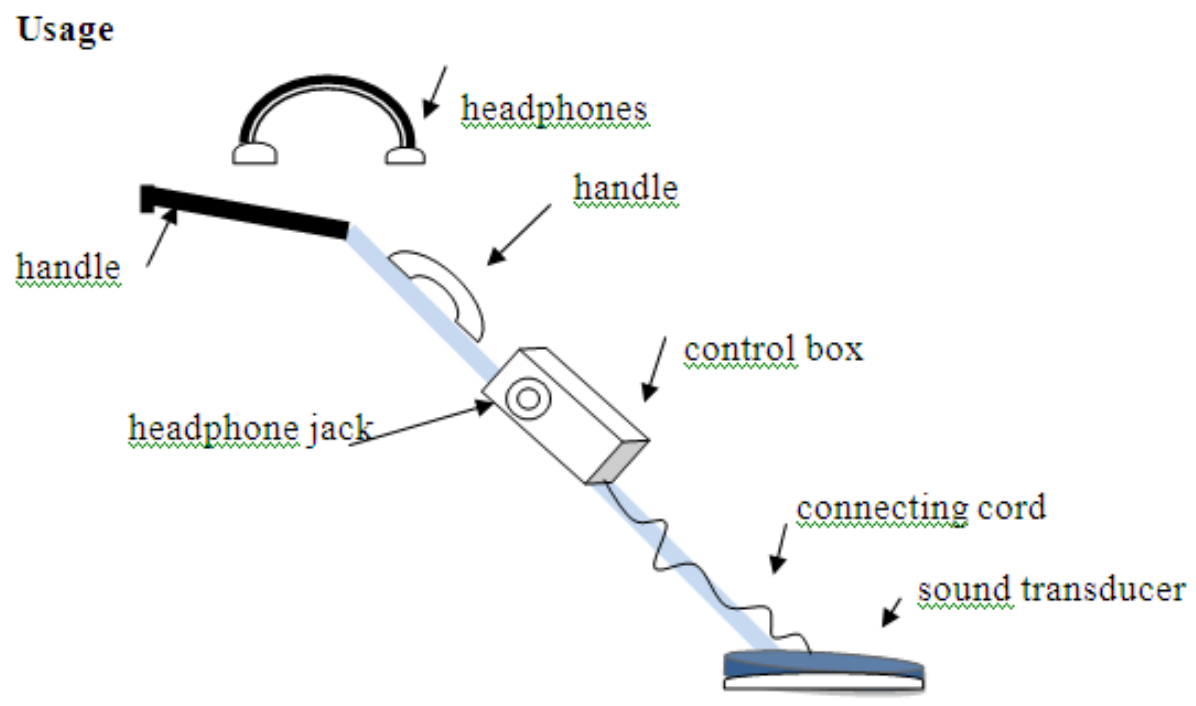

Fig. 9 view of the completed detector

The user wears the headphone, (an earphone can also be used) and move the pickup head over the surface where crocodiles are likely to have laid their eggs. When the pickup head is moved on top of the place where the eggs are buried "umph! umph! umph!" sound should be detected and passed over to the headphone. The famer will then carefully open up the nest and collect the eggs for safe hatching.

Investment: The approximate cost for the completed device is as follows:

\begin{tabular}{|c|c|}
\hline Description & Amount in US dollars \\
\hline Electronic components & 18.00 \\
\hline Headphones & 07.00 \\
\hline Microphone/pickup head & 05.00 \\
\hline Casing (enclosure) & 06.00 \\
\hline Mounting structure & 08.00 \\
\hline Total & 44.00 \\
\hline
\end{tabular}

\section{CONCLUSION}

As shown by results above this project can be used to alleviate the loss experienced by crocodile farmers every time they have to harvest their eggs. However the tests for this project were carried out under laboratory conditions, there is need to try the device out in the field. From observation it does appear that the microphone sensitivity may need adjusting, as well as the final stage of the system. The other approach would be to use an active filter; which would result in reducing the number of stages since the filter design will perform two functions, that of filtering as well as the function of amplifying the signal from the microphone before it is applied to the speaker or headphones.

\section{REFERENCES}

1). Angus \& R Reptile June 1 1966. Ecology (Australian Ecology Series). Harold Heatwole. University of Queensland.

2). Cliford H. Pope. The Reptile World. Alfred A. Knopf.

3). Dennis Roddy \& John Collen. March 6 1995. Electronic Communications $4^{\text {th }}$ Edition. Prentice Hall

4). Dzoma B. M. Sejoe S. Segwagwe. June 2008. Tropical Animal Health Prod Commercial Eric Worrel. 1963. Reptiles of Australia. University of New South Wales Sydney.

5). Harold Heatwole, and Jand Tayler. 1987. Ecology of Reptiles. Surrey Beatty \& Sons Haykin. 1993 Communication Systems. West Group.

6). Hykin. 2001 Communication systems ${ }^{4 \text { th }}$ Edition. http://www.studyshare.in

7). J. E. Webb, J A Wallwork February 1979. Living Reptiles. Palgrave MacMillan. 
8). Khosa P, Imbayrwo-Chikosi VE, Hamandishe V.Hatching. Sept. 2011. Rates and Clutch sizes of Nile crocodiles (crocodylus niloticus). Tropical animal Health Prod Commercial crocodile farming in Botswana, BV.

9). Martin T E, Bassar RD, Bassar Sk, Fosntain JJ, Lloyd P, Mathewson HA, Niklison

10). AM, Chalfovi A. Naturwissenchaffen. February.2006. Evolution

11). Roy Blake. 1993. Basic Electronics Communication. West Group

12). Vergge AL, Avril A, Martin S, Mathervon N. Januarty 2007 Parent-offspring Communication of Crocodylus niloticus. Evolution 